\title{
A Founder Mutation of the BRCA1-Gene in Western Sweden
}

Zakaria Einbeigi ${ }^{1}$, Jeane Kindblom ${ }^{3}$, Lars-Gunnar Kindblom ${ }^{3}$, Tommy Martinsson ${ }^{2}$, Mart Suurkula ${ }^{3}$, Jan Wahlström ${ }^{2}$, Arne Wallgren ${ }^{1}$ and Per Karlsson ${ }^{1}$

\section{${ }^{1}$ Department of Oncology, Sahlgrenska University Hospital, Göteborg, Sweden ${ }^{2}$ Department of Clinical Genetics, Sahlgrenska University Hospital, Göteborg, Sweden \\ ${ }^{3}$ Department of Pathology, Sahlgrenska University Hospital, Göteborg, Sweden}

\footnotetext{
AIM: To study the geographical distribution of the families with the founder mutation nt3166ins5 in the BRCA1 gene. To describe the phenotype and confirm mutational status also in deceased cases.

METHOD: In the cancer counselling clinic of western Sweden (pop. 1.6 mill) about 204 families have been investigated since May 1995. More than $75 \%$ of these families have concern about familial breast and/or ovarian carcinoma. Mutations in BRCA1 and BRCA2 are assayed by Protein Truncation Test and, in case of abnormalities, a DNA-sequence determination. In 60 of the families blood samples have been obtained, and 53 of these have samples have been
}

analysed. We have also tested for mutation in archival histological material and so far we have $100 \%$ agreement with the results from blood samples.

RESULTS: In 22 families 8 different mutations were found in the BRCA1 or the BRCA2 gene. 14 of the families with mutations in the BRCA1 gene had the same mutation, an insertion of five nucleotides (TGAGA) at nucleotide 3166, yielding a stop codon. The oldest cases originate from the coastal land south and north of Göteborg. This mutation has also been described in other parts of Sweden but the families originally came from Western Sweden. The BRCA1 analysis of deceased individuals in the nt3166ins 5 families is ongoing but already we have found one young case of breast cancer without this mutation- a sporadic case.

CONCLUSION: There is a founder mutation in the BRCA1-gene clustering along the Swedish west coast. Since our data are based on referral, the mutation may have a wider geographical distribution. At present, possible cases of hereditary breast cancer are first screened for the presence of this mutation. The penetrance for both breast and ovarian cancer seems to be high in the referred families. We are planning a population-based study to analyse further the presence of this founder mutation in the population of Western Sweden. 


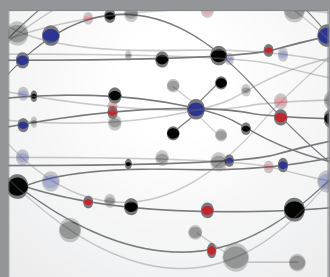

The Scientific World Journal
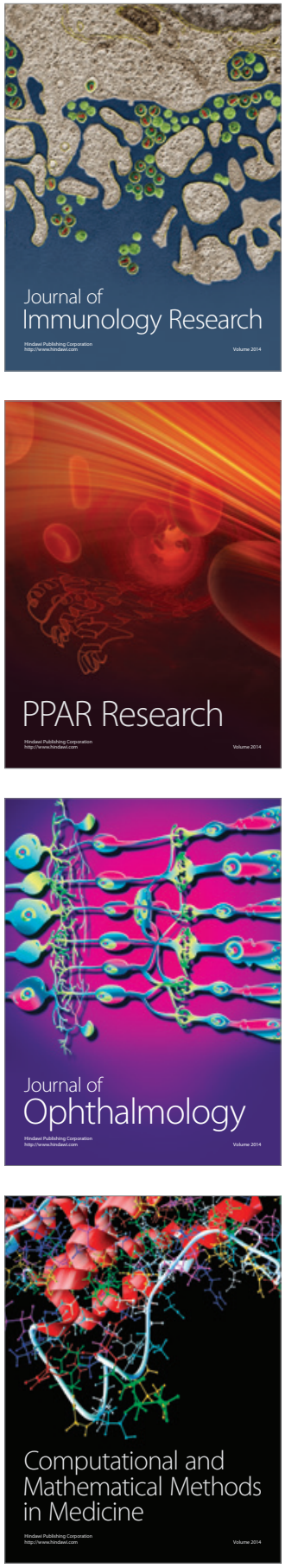

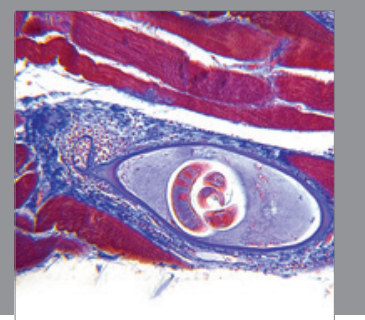

Gastroenterology

Research and Practice
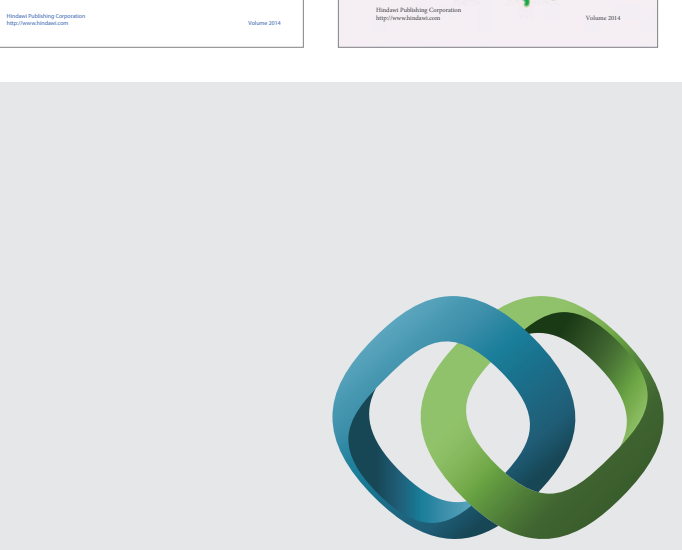

\section{Hindawi}

Submit your manuscripts at

http://www.hindawi.com
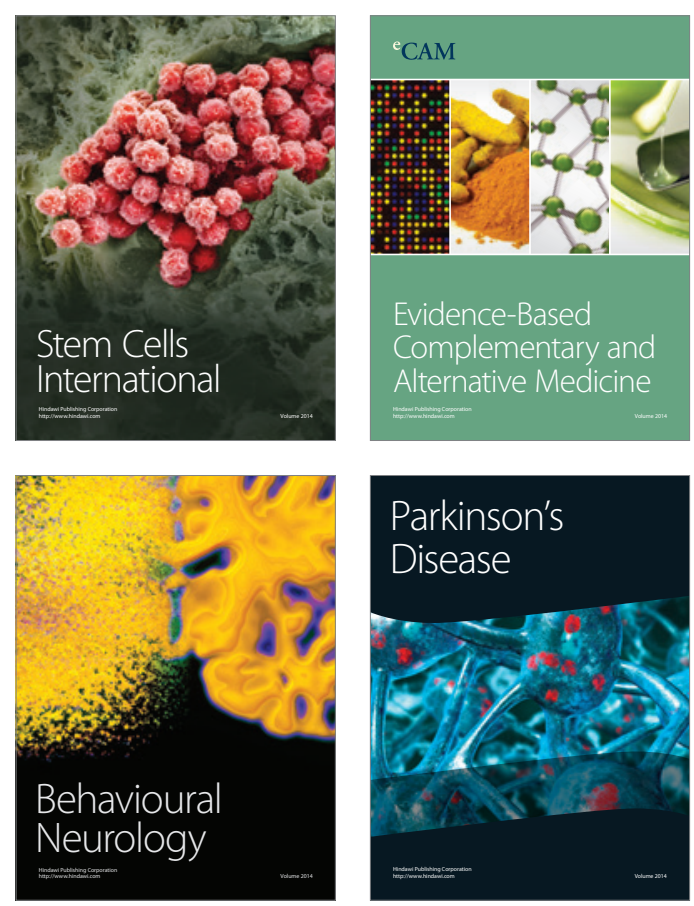

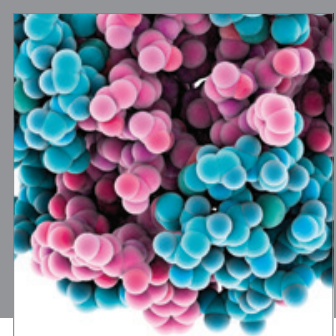

Journal of
Diabetes Research

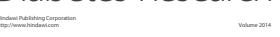

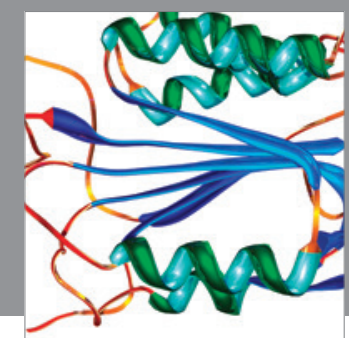

Disease Markers
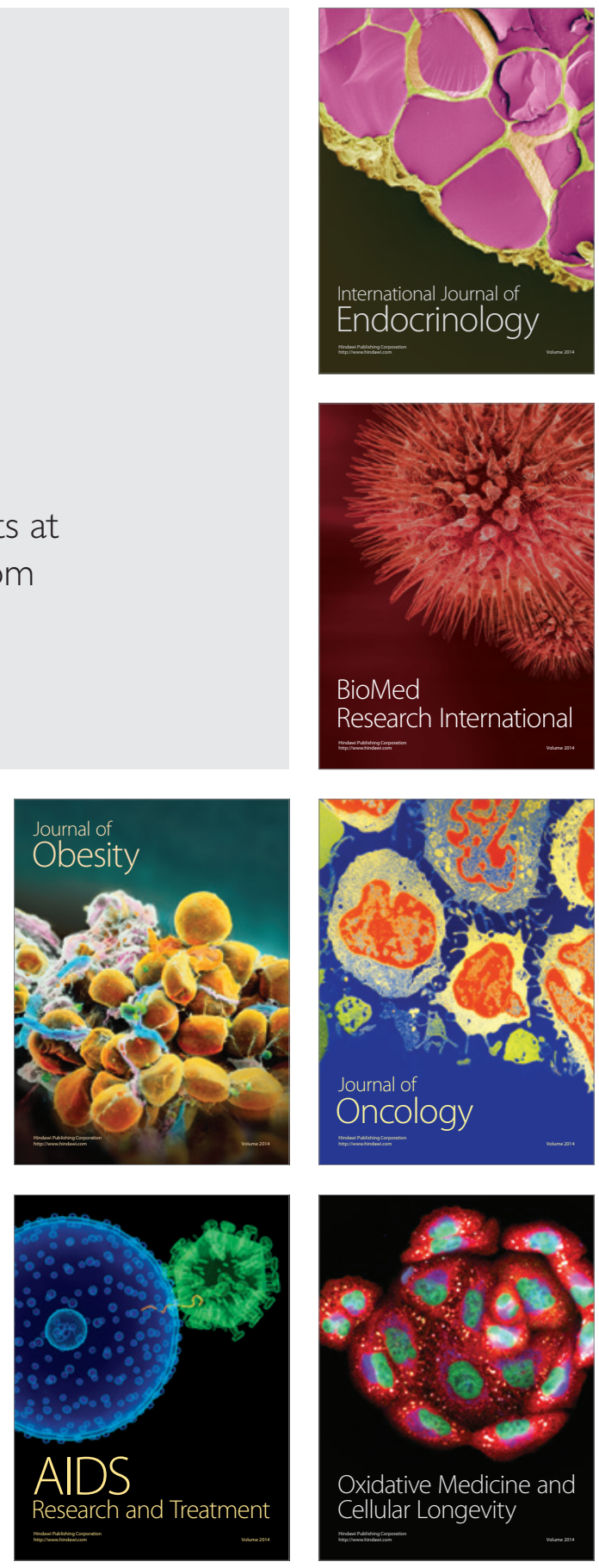